\title{
Practical Reasonableness: Some Epistemic Issues
}

\author{
Evan Simpson
}

Published online: 21 April 2013

(C) The Author(s) 2013. This article is published with open access at Springerlink.com

Practical reasoning often aims at demonstrable knowledge. Instrumental reasoning in particular seeks to determine that certain actions are effective means to some end in view. In this respect it is like scientific deliberation, which may begin in uncertainty or disagreement about where the truth resides, but resolution should be possible when the evidence has been collected and empirically assessed. Global warming is now a generally accepted fact. Similar assessments can often determine whether public policies have served their purpose. In such matters, collective deliberation satisfies ideas of rationality that expect inquiry to conclude in discovering the truth about a contested issue. In matters of moral and political intuition, though, deliberation may fail to justify the conclusion that one position is correct to the exclusion of others. It will recognize some competing views to be equally reasonable. Contrary to the assumption of rational uniqueness that cogent deliberation concerning our normative beliefs should ultimately converge on one most reasonable belief, inquiry displays fundamental normative pluralism.

Liberalism provides a good context for evaluating these propositions. As a dominant political faith it shows how cultural assumptions may constrain one's intuitive options - in a liberal society it is difficult to view slavery as other than deeply offensive - but that is far from saying that it represents the moral truth. If the following arguments are sound, it can only display moral reasonableness. The rationalistic aim of convergence upon the facts is not appropriate in the case of moral and political convictions, for which reasoned discourse is best displayed in ongoing discussion rather than demonstrable conclusions. Of course, even in science epistemic convergence is an ideal. Agreement about global warming is not universal: there are deniers who do not regard themselves as irrational. Nevertheless there are clearly truths about which they may be mistaken. Scientific inquiry can plausibly claim a progressive direction. Consideration of recent work by Hilliard

\footnotetext{
E. Simpson $(\square)$

Department of Philosophy, Memorial University of Newfoundland, St. John's, NL, Canada e-mail: esimpson@mun.ca
} 
Aronovitch and others will leave the corresponding claim for normative inquiry more deeply problematical. The factual openness typical of normative deliberation precludes anything like closure upon the truth. Nonetheless, the reasonableness of political opinions that have developed over centuries of discussion gives them ongoing credibility.

\section{Practical Disputes: Differences and Disagreements}

The fundamental point of this exploration is that normative belief properly aims at reasonableness rather than truth. In consequence, if disagreements are issues of truth and falsity then the objects of many arguments are differences that require some other mode of resolution (if they require it at all). "Disagreement" is not the noun of choice in typical matters of intuitive dispute, as when people who agree on all the facts have different intellectual or emotional responses to them. ${ }^{1}$ For example, astronomers have disputed whether Pluto is a planet but on this they are better said to differ than to disagree. Those committed to the status of Pluto as a planet do not imply that "Pluto is a planet" represents a discovery, for they are promoting a definition. If the definition is accepted, facts of nature will then decide which bodies are planets, but the principle of identification rests upon a choice that rests upon no further decisive fact. As a result, there may be divergences within the astronomical community or between that community and the general public, but the difference comes down to informed preferences for the way in which a word is to be used rather than to a disagreement about reality.

Philosophers sometimes maintain that when disputants make conflicting judgments on the basis of the same factual evidence then one of them must revise their judgment on pain of irrationality. ${ }^{2}$ If they are epistemic peers, though, possessing all the same evidence and being equally able to reason from it, what is the basis of this requirement? The question is a live issue in epistemology, but it does not arise where judgments reasonably differ rather than compete as true or false. The issue then is not rationality but reasonableness and whether recognizing faultless differences of belief comes at an unacceptable cost. It may appear to in cases of moral and political conflict but a more benign view can be defended: Many such conflicts define intelligent options rather than constituting contradictions, implying the permanence of moral and political differences and warranting philosophical satisfaction with reasonableness when practical disputes amount to differences where neither disputant need be mistaken. Learning how to differ without disagreeing then emerges as a virtue within much practical reasoning.

Acquiring this virtue will include the ability to distinguish reasonable differences from stubborn commitments. One's normative beliefs will not be grounded upon mere preferences as non-cognitivist forms of expressivism suppose. Moral and

\footnotetext{
${ }^{1}$ Of course, one can select a vocabulary in which "disagreement" does play this role, as in Allan Gibbard, Thinking How to Live (Cambridge, Mass.: Harvard University Press, 2003), pp. 65-68. There is no ideally perspicuous language.

2 The case is laid out by Peter van Inwagen, "We're Right. They're Wrong," in Richard Feldman and Ted A. Warfield, eds., Disagreement (Oxford: Oxford University Press, 2010), pp. 10-28.
} 
political disputants will not simply rationalize the facts in favour of their intuitions. Instead they will listen to the reasons for competing intuitions and be prepared to change their mind. This capacity is especially evident on an historical scale. Consider the belief in human dignity that has become deeply embedded in much contemporary thinking as part of the ethos of modern liberal societies. A view of all men as created equal is compelling in such societies because it expresses a developed sense of respect for the moral worth of other persons. To be sure, the process of development has taken generations of interpretative discussion. The view is not now acceptable unless "all men are created equal" clearly refers to all men and women in virtue of their common humanity. The process of making its practical meaning explicit includes further issues of scope, such as the age of majority. The ideas of dignity, equality and moral worth thus belong to a project under construction as part of an ongoing conversation and developing narrative. The cogency of these ideas does not arise from pre-established verities but from "openended reasoning from tradition." 3 This is a clear example of establishing reasoned positions from which it is not possible to go back, but close examination of this reasoning will show that it is not truth-apt discourse.

Simon Blackburn takes another position in suggesting that we know that slavery is wrong when no further facts will change our minds about it: there is no epistemic improvement that will lead us to abandon the belief that it is wrong. ${ }^{4}$ He rightly notes the difference between certainties of this kind and more tentative commitments, such as favoring a minimum wage. Given more expertise in economics, the minimum wage is a policy about which one might change one's mind, so that suitable intellectual modesty will prevent one from claiming knowledge in this case. About slavery, by contrast, Blackburn holds that talking about knowledge and truth can be permitted. However, the philosophical right to truth is not so easily earned. If Blackburn's view reflects reasoning from tradition, then it is intellectually questionable from the standpoint of traditions in which human trafficking is practiced. Even within the liberal project proclaiming the truth that people are morally equal is a dubiously strong interpretation of regarding an opinion as irreversible. One might insist that nothing would change one's mind about same-sex marriage but later find that one's ostensible knowledge had disappeared upon learning that a son or daughter was gay. In any event, insisting upon the truth of any normative claim is insufficiently motivated as long as it is possible to strive for reasonable commitments rather than say that some moral and political norms are now incontestable objects of knowledge.

A look backward provides a useful context for considering Blackburn's position. Imagine that $18^{\text {th }}$-Century Americans had consented to continue recognizing states' rights in the matter of slavery and that the South continued to differ from the North about the practice. Would it be appropriate to suggest that under these circumstances there was no clear disagreement? The very existence of the

\footnotetext{
${ }^{3}$ Hilliard Aronovitch, "How Liberals Can Explain the Moral Errors of Past Eras and Answer Bernard Williams," Journal of Value Inquiry, vol. 46, no. 3, 2012, p. 344.

4 Simon Blackburn, Ruling Passions: A Theory of Practical Reasoning (Oxford: Clarendon Press, 1998), pp. 306-307.
} 
American nation arguably depended upon commitment to the proposition that all men are created equal. While half slave and half free, the nation had a cancer eating away at that idea within the body politic, showing that issues in conscientious dispute are not always subject to compromise as if they represented reasonable differences. Rather, the health of the society depended upon its commitment to embracing the moral truth about slavery. ${ }^{5}$ But this cannot be right. There was no such general social commitment. Rather, in the absence of a universally recognized truth, there was civil war. The dispute might have been amicably settled in the long run if it had focused upon clearly factual issues - whether African slaves were naturally submissive or unequal to their owners in native intelligence, for example but settling these issues does not establish the normative position that slavery is a hateful practice. In a liberal society the jury of public opinion certainly places the onus of argument on the pro-slavery side: If anything is a moral fact it is that slavery is wrong. Nevertheless, this is a demanding condition to satisfy. The wellestablished openness of recognized facts to alternative normative judgments warrants philosophical hesitation about claiming truth for any of these judgments. Fortunately, hesitation exacts no high epistemic price if judgments of right and wrong can be recognized as reasonable opinions rather than expressions of noncognitive preferences. The existence of a legitimate onus can represent superiority in argument rather than simple political or military success. Expressions of moral approval and disapproval are then cognitively justified.

Blackburn's knowledge claims are an apology for ordinary language. If it is all right as it is, and if it permits speaking of moral truth and knowledge, then so be it. This defense does seem to sacrifice some philosophical rigor, however. It makes it challenging to distinguish meta-ethical expressivism from moral realism, for example. It is therefore worth examining some more theoretically well-founded attempts to show that moral truths can overcome normative differences. Three such attempts are especially interesting, particularly because they effectively represent elements of the liberal project. One (communicative rationalism) is embodied in procedural accounts of sound practical deliberation, another (discursive nonnaturalism) in a meta-ethical alternative to the cognitivist expressivism defended here, and a third (moral universalism) in a contrast between ethical beliefs that are matters of convention and moral beliefs whose content must be regarded as objects of knowledge. Each of these accounts propounds an epistemically robust conception of normative reasoning. Their ultimate failure supports satisfaction with normative reasonableness over moral truth.

Procedural accounts of deliberation build upon the broadly accepted model of rational discourse that free, discursive, empirical inquiry will eventually lead to theoretical agreement after exhaustive testing against the describable facts. Corresponding to this conception of deliberation in scientific communities, a comparable ideal of practical reasoning holds that legitimate moral and political discourse occurs only given general commitment to rules of debate that permit every interested party to take part in deliberation, introduce any proposal, question

\footnotetext{
5 Compare Garver, For the Sake of Argument: Practical Reasoning, Character, and the Ethics of Belief (Chicago, Ill.: University of Chicago Press, 2004), p. 16.
} 
any claim and express one's attitudes and needs. ${ }^{6}$ Conclusions that depart from this thoroughgoing democratic egalitarianism - for example, decisions that would leave a nation half slave and half free - then mark obvious defects of discursive deliberation. The procedural norms thereby constrain unjust outcomes by recognizing basic moral truths that identify human freedom and equality as presuppositions of sound deliberative commitments. We should therefore postulate certain well-founded moral agreements that need only be made explicit in order for them to constrain the inevitable wealth of ethical difference that a pluralistic society has to manage.

An obvious difficulty for this communicative rationalism is that its procedural ambitions are compromised by the substantive commitments that build in moral agreement. The practice of discourse is taken to presuppose the obligation that all participants be respected as equals in virtue of possessing human dignity: "All persons as such possess a dignity we are obligated to respect and promote." 7 This argument fails because human dignity justifies universal respect but appealing to the dignity of every person expresses an article of political faith rather than a demonstrable truth that could enable discursive procedures to extend their epistemic success to moral as well as scientific agreement. (To be sure, a similar argument could be made against scientific discourse, for which alternative theories can be consistent with all the known facts, but that does not make the case for a procedural approach to moral truth.)

The question-begging element of communicative rationalism is addressed by the second discursive approach to the resolution of moral differences. A venerable theory of interpersonal moral agreement develops truth-based conditions for normative belief by construing justifying reasons as non-natural facts. All forms of this theory lead straightforwardly to a robust normative realism. As for other nonnaturalisms the facts are to be known through a kind of intuition, but while intuitions notoriously differ the thesis need not prove epistemically barren. To the contrary, it should provide an appealing explication of the way in which the liberal ethos has developed through centuries of ongoing conversation, yielding an egalitarian narrative that is capable of correcting prejudiced personal intuitions. Generations of development have given the concept of human dignity an incontestable core of application - to men and women, young and old, black and white - that rules out certain discriminatory practices as unquestionably offensive. A discursive non-naturalism thereby becomes an appealing route to the moral facts that provide the foundation for liberal society.

A view of this kind shows how moral intuitions can represent normative truths through a form of seeing rather than inference. Liberal perceptions are refined and clarified by reliable processes of deliberative development in contrast to judgments that express personal preferences or arise from evolutionary adaptations bearing no

\footnotetext{
6 Jürgen Habermas, Moral Consciousness and Communicative Action (Cambridge, Mass.: MIT Press, 1990), p. 89.

7 Walter Okshevsky, "On the Epistemic Grounds of Moral Discourse and Moral Education: An Examination of Jürgen Habermas's 'Discourse Ethics,'” in Chris Higgins, ed., Philosophy of Education 2004 (Urbana, Ill.: University of Illinois Press, 2005), pp. 177-178.
} 
resemblance to any moral realities. ${ }^{8}$ Cultural reflection yields definitive criteria of evaluation that are cognitively robust. Unfortunately, though, in seeking to determine normative reality through a particular ethos, it will seem necessary to develop a relativistic conception of truth or conclude that one culture's set of ethical judgments is uniquely attuned to the moral facts. The first of these positions conflicts with the principle of rational uniqueness and will not be further considered here. The second is a version of moral universalism that warrants closer attention. The next section therefore explores a possible distinction between ethical beliefs that cannot do better than reasonableness and moral beliefs that successfully claim universal truth or validity.

The point of the ensuing discussion is to consider the possibility of epistemically truth-apt beliefs in matters of morality in contrast to the disputable beliefs typical of ethical commitment. After all, there is nothing on the face of moral discourse that renders it obviously prone to irresolvable conflicts. Where the norms of public reason require all views to be heard, all issues to be thoroughly discussed and consensus to be sought, it can be responsibly doubted that moral disagreement is a permanent feature of human existence. Ethical difference can remain. Practical reasonableness and rationality in a pluralistic society would then conform to a simple analogy: Ethics is to morality as difference is to disagreement. Developing the distinction between moral agreement and disagreement and ethical consensus and difference will sharpen this proposal. In the end, though, moral universalism will fall short of establishing the possibility of normative knowledge.

\section{Ethics and Morality}

Assume for purposes of argument that norms of good reasoning mark unresolved moral disagreements as failures of practical thinking. For this assumption to be plausible its scope must be constrained by distinguishing a recognized class of differences from disagreements, leaving room for some ongoing diversity of judgment. Characterizing the relevant differences as ethical rather than moral implies that moral consensus is consistent with ethical pluralism. Like languages, ethical systems tend to diverge. Human creativity and critical acumen perturb established ways of life and patterns of commitment, challenging convention and creating diversity in manners, modes of dress, dietary habits, religious observances, familial pieties and customary behavior generally. In a competitive engagement between alternative customs, it is not to be expected or even desired that deliberative discussion will resolve the differences. No single ethos has a monopoly on the good life or legislates for all humanity. Ethical differences thus distinguish various individuals and communities whose diverse ways of life have a presumption of permissibility within the constraint of morality, about whose universal requirements alone should agreement be expected. Reasonable ethical differences do not then support moral relativism.

\footnotetext{
${ }^{8}$ For a recent such account see Sabine Roeser, Moral Emotions and Intuitions (Basingstoke: Palgrave Macmillan, 2011).
} 
Most ethical ideals that endure over generations can be coherently stated and attractively described. Various ways of life are suitable objects of pride and admiration. At the same time, as modern parents often find in commending social practices to their children, particular ways of life can prove difficult to justify when others challenge them. Mill therefore invited us to recognize of our own ethical worldviews and the dissenting visions of other people that "mere accident has decided which of these numerous worlds is the object of [our] reliance." 9 The contingency of many normative commitments does not disturb our comfort within an ethical community where we can identify actions and lives that warrant esteem for nobility and shame at dishonour, but gaining a critical perspective makes us rightly hesitate to suppose that we believe as we do because our beliefs are better grounded than those supporting alternative ways of life. Ethical pluralism clearly displays the contestability of beliefs that require the support of engaging narratives to which there can be reasonable rivals. In contrast to great bodies of belief in mathematics and science that are rarely subject to significant disagreement, disputes flourish when there is no decisive evidence for judgment. Arguably, there is no such thing as faultless disagreement, but no-fault differences remain when all of the describable facts have been taken into account. As a result, some people may confidently do certain things that others would avoid but can recognize as situated within a plausible story of responsible decision. Even if they deplore those things, they can recognize them as morally permissible. The important question is how to understand the relationship between ethical acceptability and moral requiredness. Recognizing normative contingencies and hesitating to assume that one's ethical beliefs are better grounded than others' are philosophical virtues, but they do not rule out distinguishing between what is conventionally acceptable and what is morally correct.

The tidy way of stating the distinction is to say that morality defines the limits of permissible pluralism: it identifies a set of obligations addressed to all persons everywhere. For example, Mill's defence of liberty is consistent with great personal and social differences, but only within the constraint of the harm principle, which is universally binding. The condition of universality casts morality as an impartial authority independent of particular worldviews and ways of life. Given this conceptual marker, one can propose a clear line between morality and ethics. The former will include matters subject to rational and universal agreement, including such general principles as seeking the greatest good for the greatest number and treating human beings as ends in themselves, together with further principles for resolving conflicts when they occur between these primary requirements. Since these ideals are integral to liberalism, it can claim to be the ethos that comes closest to moral truth. More generally, ethical life and many of its differences can arguably be accommodated within these deontological and utilitarian moral constraints.

This proposal rules out cognitivist expressivism in moral theory or restricts it to ethical considerations, but the supporting rationale represents a useful distinction between ethical particularity and moral universality too tidily. The problem can be seen by hesitating to accept the universalistic conception of morality uncritically and focussing first upon the emotional markers that can be used to distinguish ethics and

\footnotetext{
9 John Stuart Mill, On Liberty, ed. Alburey Castell (Northbrook, Ill.: AHM Publishing, 1947), p. 18.
} 
morality. Whereas ethical ways of life are characterized by pride and admiration among their practitioners, the utilitarian and deontological principles characteristic of contemporary conceptions of morality are associated with emotions of beneficence and rectitude. Moral psychologists observe that aptitude for the latter sentiments enables us to respond to others sympathetically and to respect our equals, and social scientists explain this make-up by noting the adaptive benefits of intuitive cooperation: Inspired by natural benevolence we readily assent to principles of supporting others' welfare; and inspired by respect for others we readily avoid treating them as tools for our purposes. Against this background the distinction between ethics and morality does not suggest the superior rationality of moral considerations. Rather, the division corresponds to emotions that resist universalizability and those that permit it. On the one hand we find communal affections that rest upon comparisons. Pride and admiration imply distinctions that do not lend themselves to universality, since only some can excel in any given activity or pursuit. On the other hand we find emotions that are universalizable, providing avenues of moral concern for the general welfare and the recognition of human equality. Different parts of the repertoire of human emotions thus identify the spheres of ethics and morality respectively. Only the moral emotions are universalizable, but this is no particular distinction because universalizability differs crucially from universality.

The deliberative resources available in liberal cultures encourage general assent to universal principles of human welfare and equality, but this is not the unavoidable agreement that attaches to statements whose truth should be recognized by rational beings. The attribution of universality represents only one of the possible forms of moral thinking, which may be extended to all persons as objects of sympathy and respect but which have usually remained parochially focussed on a limited group. Most people pity the pains they observe and normally want to avoid causing others to suffer. Most people respect their social peers and want to deal fairly with them. It is a further step to avoid harm to all persons and extend the protections of moral personhood to everyone. The liberal morality that includes universal ascription of moral personality is a feasible expression of sympathy and respect and one in which liberal cultures can reasonably take pride. However, the universalisation of these responses is not compelled by ascertainable facts about sapient or sentient beings. Rather, universalized beliefs can be understood as the particular form of the moral commitments sanctioned by our ethical life. As Charles Taylor observes, "the premises of ... moral reasoning can ... appear to be of a quite different provenance from those that deal with qualitative contrast," but "[w]hat is really going on is that some forms of ethical reasoning are being privileged over others because in our civilization they come less into dispute or look easier to defend." ${ }^{10}$ Bernard Williams can be read as making a similar point in characterizing morality as "a particular development of the ethical.", 11

${ }^{10}$ Charles Taylor, "The Diversity of Goods," in Philosophy and the Human Sciences (Cambridge: Cambridge University Press, 1985), p. 241. Taylor's comment is part of a defence of "languages of contrast" that tend to get short shrift in utilitarianism and Kantianism.

${ }^{11}$ Bernard Williams, Ethics and the Limits of Philosophy (London: Fontana, 1985), p. 6. Williams does not attempt to define what counts as an ethical consideration but treats ethics as a broad notion against which to situate the special, modern system of morality. 
Taylor and Williams suggest nice ways of questioning the rationalistic ambitions of moral universalism. Without going deeply into their detailed positions, their observations permit linking these ambitions to sympathy and respect, making them objects of cognitive assessment without implying that this assessment will display an inherently progressive direction. Aronovitch, to the contrary, suggests that looking more closely at the conversation of modernity discloses resources that support this direction: Analogical reasoning in particular explains and justifies the moral commitments liberals uphold. Properly employed, such reasoning addresses "past errors such as the acceptance of slavery" by remedying "an intellectual deficiency, whereby persons or situations that are relevantly similar are judged differently, and a moral deficiency of due sympathy for others as human beings is absent." ${ }^{12}$ Richmond Campbell and Victor Kumar similarly suggest that liberal "intuitions about the moral status of women, persons of color, and other groups that historically have been treated as unworthy of respect" are supported by "consistency reasoning" as "a mechanism that functions to resolve practical conflict among our emotion-infused moral judgments." 13

These observations certainly show that analogies give reasons, and these reasons can be generally convincing after political struggles for an extension of sympathy and respect have been won, but it would be a mistake to conflate hard-won social gains with an inherent direction for reasonable opinion. Almost anything can be likened to anything in some respect, leaving the judgment that they are relevantly similar logically open to question. Analogical reasoning differs in this way from formal inference, where arguments about superficial comparisons do not properly arise. Moreover, in so far as moral judgments are emotion-infused, they share the contestability of analogical reasons, and such contests can be settled in different ways. Liberals do not know whether the struggles of women for equality in Islamic societies will be successful. Even within liberal cultures the debatable scope of universal inclusion is evident in questions about merely sentient animals. If vegetarians convince most people that animals enjoy universal rights, will looking back to the present reveal the "past error" of eating the flesh of slaughtered creatures or will it rather express a reasonably revised idea of "due sympathy"? The rise of vegetarianism will settle an issue about the normative standards acceptable to a set of co-deliberators, but that is not to say that certain ethical beliefs have become moral knowledge that all rational agents must accept. At any given time ethical solidarity may hide potential normative differences, but when they emerge there is no way of confining reasonableness within the mold of truth. In short, the attempt to identify universal moral propositions recognized as true by ideally rational agents does not hold much promise of success.

The practical expressions of this disappointment include a form of intellectual modesty when normative differences complicate the practical concerns of life. Suppose that there is need to settle a dispute about public policy, such as whether to countenance human euthanasia. Even if there is ethical consensus on a principle of

\footnotetext{
12 Aronovitch, "How Liberals Can Explain the Moral Errors of Past Eras," op. cit., p. 344.

13 Richmond Campbell and Victor Kumar, "Moral Reasoning on the Ground," Ethics, vol. 122, no. 2, 2012, pp. 274-275 and 300.
} 
universal human worth and the implication that innocent persons should not be unnecessarily harmed, it does not determine how to assign harms to permanently unconscious people or terminally ill people who want to die. Rather than supposing that there is a truth of this matter, it is possible to accept a political solution without compromising one's conscience by acceding to an unreasonable decision. In this sense it is not a mistake to submit one's considered judgment to the majority. Doing so would be unacceptable if political minorities were expected to conclude that they were mistaken, but that would imply that they regarded their practical judgments as true. They should not do this if reasonable commitment is comprised of considered intuitions that others may dispute. One may feel that permanently comatose persons should be protected, but intellectual modesty should enable one to live with the alternative decision, just as one can live with other choices one would not make oneself. Political acceptability will of course be easier if ethical pluralism takes institutional forms that free minorities from unnecessary restrictions on the exercise of their beliefs. For example, separate hospitals might be able to publish different policies on euthanasia, each expressing the practices favored by their different ethical constituencies. Similar reflections should apply to many other examples of issues that require political resolution. The underlying point is that the epistemic properties of intuitive belief support the virtue of ethical compromise. Such a compromise is neither a strategic modus vivendi nor convergence on the truth. It is a practice made acceptable by recognizing the reasonableness of different positions. ${ }^{14}$

H. J. Leland and Han van Wietmarschen use the concept of intellectual modesty to refer to "a matter of how a citizen understands the intellectual resources and capabilities of those with whom she disagrees." 15 Reasonable citizens recognize that others endorse intuitions that conflict with their own and see no prospect of convergence upon a single answer. Since such modesty is consistent with the themes of the present discussion, it is interesting to consider whether it is conceptually sustainable given that people generally are at most tempered pluralists. Even very tolerant popular opinion resists accommodating some marginal ethical stances as reasonable. In spite of our freedom of thought and discussion, well-acculturated members of liberal societies may find it difficult to explore some things openmindedly. Discussions of taboos or abominations - such as cannibalism, paedophilia and slavery - are acceptable only in fictional, historical or anthropological contexts, not as live options in modern societies. No one who advocates human slavery is likely to be worth listening to, precluding talk of alternatives here and suggesting that some ways of life must be regarded as false for purposes of action. A few benighted individuals may defend sex with consenting children or dining on the dead as victimless practices, but they lie outside acceptable society, whose boundaries define limits beyond which odious commitment is not tolerated and may be viewed as truly wrong.

\footnotetext{
${ }_{14}$ Andrew Lister, "Public Reason and Moral Compromise," Canadian Journal of Philosophy, vol. 37, no. 1, 2007, p. 18.

${ }^{15}$ Or, in the language of this essay, "differs." See R. J. Leland and Han van Wietmarschen, "Reasonableness, Intellectual Modesty, and Reciprocity in Political Justification," Ethics, vol. 122, no. 4, 2012, p. 722.
} 
An important issue lies here. The jury of public opinion identifies reasonable people according to prevailing norms of thought and behavior. These norms, we have observed, are products of a long cultural conversation. They are provisionally fixed points but remain open-ended. In consequence, they define what will be tolerated but are also subject to challenge by reformers and dissenters who seek to amend them. This possibility is grounds for the philosophical modesty expressed in finding "not tolerated" and "truly wrong" an awkward conjunction of ideas. Abominations have a checkered history. People have differed and will continue to differ about what practices are hateful, what makes them hateful and why. There are worlds in which slavery has been supported by supposing the system to be beneficial for all participants. This position is incredible in modern liberal societies, where reasons justifying hatred of the practice have become inherent in popular wisdom; but because justifying reasons can always be resisted by a dissenting faction, the risk of civil conflict can never be entirely removed. As a result, the refuge of truth is difficult to resist, but the argument of this essay is that the philosophical analysis of practical reasoning has not earned this sanctuary. It is not facts of human dignity and equality that justify liberal opinion so much as informed sympathy with the victims of human trafficking, respect for all one's fellow human beings, and love of neighbor. Good liberal reasoning is best encouraged philosophically by offering arguments and analogies that give reasons for universalizing these sentiments and by explicating the meta-ethical grounds of intellectual modesty. It is best encouraged politically through liberal civic education and inclusive public deliberation. As long as conversation continues, disputes do not become states of war and leave compromise open. The assumption that moral disputes mark failures of practical reasoning is nevertheless mistaken, for there is no sustainable boundary between ethical difference and moral disagreement.

\section{Conclusion}

Jane Austen's ironic reference to "a truth universally acknowledged" is a shrewd reminder that ethical imperatives are tied to particular forms of moral life. ${ }^{16}$ The philosophical lesson is to be cautious about assuming that moral truths are the grounds of sound action. This assumption is challenged by ethical intuitions that resist complete factual analysis and empirical demonstration. In matters of practical reasoning, reasonableness is often the best object of our reliance.

Open Access This article is distributed under the terms of the Creative Commons Attribution License which permits any use, distribution, and reproduction in any medium, provided the original author(s) and the source are credited.

\footnotetext{
16 Jane Austen, Pride and Prejudice [first published in 1813]: "It is a truth universally acknowledged that a single man in possession of a good fortune must be in want of a wife."
} 